\title{
Granulomatous Interstitial Nephritis: A Rare Cause of Acute Kidney Injury
}

\author{
Sajad Ahmad1, Muhammad Anees¹, Hina Akbar1 and Noreen Akhtar²
}

\begin{abstract}
Acute granulomatous interstitial nephritis $(\mathrm{GIN})$ is a rare cause of acute kidney injury (AKI) but treatable. It is present in 0.5 to $0.9 \%$ of native renal biopsies. Treatment with moderate dosage of steroids is associated with good prognosis. We herein review a case of a 48-year lady having AKI following drug-induced damage [non-steroidal anti-inflammatory drugs (NSAIDs) and antibiotics]. Her renal functions did not improve after one month of drug withdrawal, so renal biopsy was done that showed acute GIN. She was treated with intravenous then oral steroids that completely resolved AKI.
\end{abstract}

Key Words: Acute kidney injury, Acute granulomatous interstitial nephritis, Steroids.

\section{INTRODUCTION}

Granulomatous interstitial nephritis (GIN) is a rare histologic diagnosis that is present in between 0.5 and $0.9 \%$ of native renal biopsies. ${ }^{1}$ It can present with varying magnitudes of renal impairment and low-grade proteinuria, and can be severe enough to necessitate renal replacement therapy. ${ }^{2}$ Treatment with a moderate dosage of prednisolone is associated with a good prognosis. $^{3}$

This present report describes this rare condition in an adult lady.

\section{CASE REPORT}

A 48-year lady presented with history of nausea, vomiting and shortness of breath. Vomiting was gradual in onset, not related to food intake, progressive with no history of abdominal pain, jaundice, diarrhea and constipation. Shortness of breath was also gradual in onset and was associated with dry cough. There was no history of chest pain, orthopnea, paroxysmal nocturnal dysponea, oliguria, rash, peripheral edema, arthralgias, oral or nasal ulcers, and fits. These complaints were preceded by fever about one month back that had lasted for five days. It was associated with sore throat, dry cough; and relieved by taking medication from a general practitioner that included Ibuprofen and co-amoxiclave. History of diabetes mellitus, hypertension and tuberculosis was negative with no significant family history. She was menopausal for two years.

1 Department of Nephrology, Mayo Hospital, King Edward Medical University, Lahore, Pakistan

2 Department of Pathology, Shaukat Khanum Memorial Cancer Hospital and Research Center, Lahore, Pakistan

Correspondence: Dr. Sajad Ahmad, Department of Nephrology, Mayo Hospital, King Edward Medical University, Lahore, Pakistan E-mail:dr.sajjadahmad@gmail.com

Received: April 12, 2018; Accepted: July 10, 2018
On examination, she had blood pressure of $160 / 90$ $\mathrm{mmHg}$ with no postural drop, regular pulse rate of 88 /minutes, afebrile with respiratory rate of 18 /minutes. There was no peripheral edema. Cardiorespiratory examination revealed normal vesicular breathing and normal heart sounds. Rest of general and systemic examination was normal.

Her laboratory investigations revealed serum creatinine of $5.94 \mathrm{mg} / \mathrm{dL}$. Urea level was $106 \mathrm{mg} / \mathrm{dL}$ but there were no previous investigations available and this was the first reading. Serum sodium was $137 \mathrm{mmol} / \mathrm{L}$, potassium was $4.4 \mathrm{mmol} / \mathrm{L}$, alkaline phosphatase was $254 \mathrm{U} / \mathrm{L}$, alanine aminotransferase was $60 \mathrm{U} / \mathrm{L}$, aspartate aminotransferase was $39 \mathrm{U} / \mathrm{L}$, total bilirubin was $0.8 \mathrm{mg} / \mathrm{dL}$, serum albumin $3.8 \mathrm{~g} / \mathrm{dL}$, serum calcium was $8.7 \mathrm{mg} / \mathrm{dl}$. Her hemoglobin was $11.4 \mathrm{~g} / \mathrm{dL}$, white blood cell count was $8.4 \times 10 \% / \mathrm{dL}$; platelet count was $210 \times 10 \% / \mathrm{dL}$. Urine complete examination revealed proteinuria $+1,10-20$ red blood cell/high power fields and no red or white cell cast. Renal ultrasound revealed bilateral normal size kidneys with no stones or hydronephrosis. Chest X-ray was unremarkable. Glomerulonephritis (GN) workup was negative that included hepatitis $B$ and $C$, complement level C3 and C4, anti-streptolysin O (ASO) titers, antinuclear antibodies (ANA).

On the basis of history, examination, and initial investigations, the differential diagnosis was AKI due to: acute interstitial nephritis, acute tubular necrosis, and rapidly progressive glomerulonephritis secondary to post-infectious glomerulonephritis. Renal biopsy was performed that disclosed 15 glomeruli that were normocellular with mild to moderate tubular atrophy. In the interstitium, there were confluent granulomas (noncaseating) with Langerhans type multinucleated giant cells as shown in Figure 1. No necrosis was seen. Blood vessels have mild fibro-intimal proliferation. Immunofluorescence was negative.

On the basis of history, examination, investigations, and renal biopsy, final diagnosis of acute granulomatous 


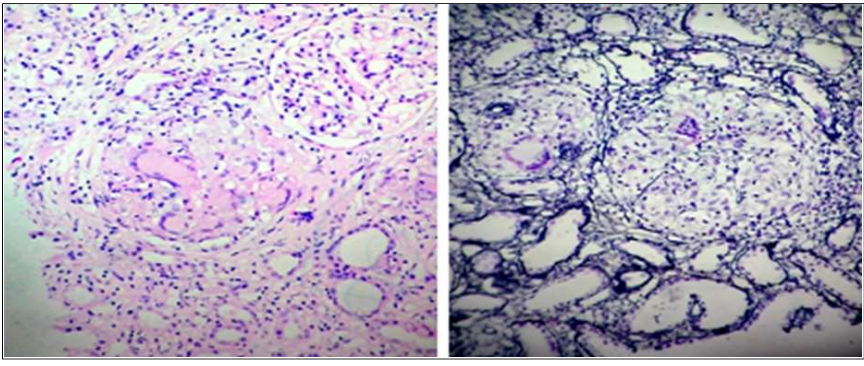

Figure 1: Numerous well epithelioid non -necrotizing granulomas with Langhan type of giant cell.

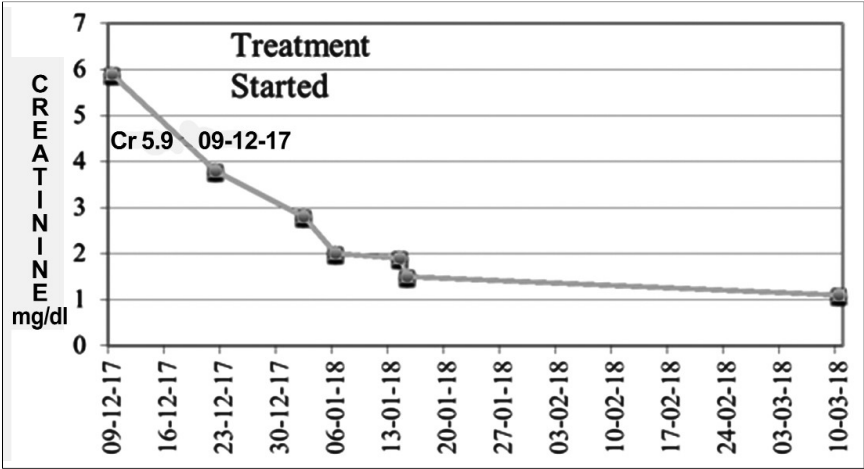

Figure 2: Improvement in serum creatinine following steroids treatment.

interstitial nephritis was made. Most likely etiology was the drugs given for her upper respiratory tract illness as other causes of acute GIN worked up were found to be negative. She had no history of contact to tuberculosis. She had no appreciable lymphadenopathy, serum angiotensin converting enzyme (ACE) level was normal and no evidence of hypercalcemia was found. Her autoimmune history and profile was also negative. C-Reactive protein level was normal. Cytoplasmic antineutrophil cytoplasmic autoantibodies (c-ANCAs) and perinuclear antineutrophil cytoplasmic autoantibodies (p-ANCAs) were negative.

She was given intravenous methyl prednisolone $0.5 \mathrm{gm}$ for three days, followed by oral steroids (tab. prednisolone $30 \mathrm{mg} /$ day), her body weight was 61.2 kilograms. Other prescribed medication include tab. domperidone $10 \mathrm{mg}$, tab. ranitidine $150 \mathrm{mg}$, chewable calcium carbonate and tablet nifedipine $20 \mathrm{mg}$ to control her blood pressure. Patient remained in follow-up with improving renal function. Her serum creatinine improved to $1.5 \mathrm{mg} / \mathrm{dL}$ after one month; and after two months, it was $1.1 \mathrm{mg} / \mathrm{dL}$ as shown in the Figure 2. Steroids were tapered off and she was taking nifedipine for her persistent blood pressure that did not improve after treatment.

\section{DISCUSSION}

Acute interstitial nephritis (AIN) is an acute, often reversible disease characterised by inflammatory infiltrates within the interstitium. ${ }^{4}$ AIN is an uncommon cause of $A K I$ and is identified in only about $2-3 \%$ of all renal biopsy specimens. ${ }^{5}$ AIN is most often induced by drugs, particularly antimicrobial agents, proton pump inhibitors, and nonsteroidal anti-inflammatory drugs (NSAIDs). Drug-induced AIN appears to account for about $75-90 \%$ of all cases. ${ }^{4}$ Four types of drug-induced AIN have been identified depending upon the inflammatory infiltrate constitution: lymph-macrophagal, eosinophilic, plasmocytic, and granulomatous AIN. 6

If granulomatous inflammation is present in a renal biopsy, the differential diagnosis include renal tuberculosis, renal sarcoidosis, drug-induced granulomatous interstitial nephritis, and tubulointerstitial nephritis and uveitis (TINU). ${ }^{2}$

There are limited reports of GIN with NSAIDs; and antibiotics are presumed the most likely causative agents in our patient. Javaud et al. found 7 out of 40 consecutive renal biopsies between January 1991 and February 2004 to have GIN that were considered druginduced. 7 Two of these patients were exposed to ibuprofen and tenoxicam. Penicillins (ampicillin, oxacillin and methicillin) and cephalosporins have been linked to GIN in several case reports. 2,7 However, which of these two drugs was the culprit in our case, could not be determined as both can cause GIN as they share same histopathological patterns. When the cause of AKI remains unexplained, a renal biopsy is indicated for definitive diagnosis and management. ${ }^{8}$

Treatment for GIN depends on the underlying etiology. In drug-induced GIN, treatment involves withdrawal of the offending agent, and usually a course of corticosteroids. ${ }^{9}$ The findings of mild tubulointerstitial fibrosis are associated with a more favourable response to corticosteroid therapy. 10 Joss et al. reviewed 18 cases of GIN over a period of 15 years and suggested that treatment with a moderate dosage of prednisolone is associated with a good prognosis, irrespective of the underlying cause. ${ }^{3}$

\section{REFERENCES}

1. Mignon F, Mery JP, Mougenot B, Ronco P, Roland J, MorelMaroger L. Granulomatous interstitial nephritis. Adv Nephrol Necker Hosp 1984; 13:219-45.

2. Nadri $Q$, Althaf $M M$. Granulomatous tubulointerstitial nephritis secondary to omeprazole. BMJ Case Rep 2014. 2014: bcr2014203842.

3. Joss N, Morris S, Young B, Geddes C. Granulomatous interstitial nephritis. Clin J Am Soc Nephrol 2007; 2:222-30.

4. Jerome A, Rossert EA, Fischer. Acute interstitial nephritis. In: Johnson RJ, Feehally J , Floege J. ed. Comprehensive clinical nephrology $5^{\text {th }}$ ed. Elsevier Limited, Philadelphia; 2015. p.728.

5. Goicoechea M, Rivera F, López-Gómez JM. Increased prevalence of acute tubulointerstitial nephritis. Nephrol Dial Transplant 2013; 28:112-5.

6. Pospishil' lu $\mathrm{O}$. The pathomorphology of acute drug-induced tubulointerstitial nephritis. Lik Sprava 1996; 5:94-6. 
7. Javaud N, Belenfant X, Stirnemann J. Renal granulomatoses: a retrospective study of 40 cases and review of the literature. Medicine (Baltimore) 2007; 86:170-80.

8. Lo WK, Rolston KV, Rubenstein EB. Ciprofloxacin-induced nephrotoxicity in patients with cancer. Arch Intern Med 1993; 153:1258-62.
9. Shah S, Carter-Monroe N, Atta MG. Granulomatous interstitial nephritis. Clin Kidney J 2015, 8:516-23.

10. Gonzalez E, Gutierrez E, Galeano C. Early steroid treatment improves the recovery of renal function in patients with drug-induced acute interstitial nephritis. Kidney Int 2008; 73: 940-6.

......... 